\title{
Um ensaio sobre burnout, engagement e estratégias de coping na profissão docente
}

\author{
Margarida Pocinho \\ Célia Xavier Perestrelo \\ Universidade da Madeira
}

\section{Resumo}

Investigadores, um pouco por todo o mundo, começaram a preocupar-se com o fenómeno do burnout, ao identificarem este sintoma essencialmente nas profissões que envolviam uma relação assistencial ou de ajuda, como o caso dos médicos, enfermeiros e psicólogos. Contudo, não tardou que se percebesse que este fenómeno pudesse também estar presente na profissão docente de uma forma muito significativa. A docência é, na atualidade, uma das profissões mais sujeitas a altos níveis de stresse, podendo levar ao burnout, caso se torne recorrente. Muitos docentes conseguem adaptar-se e reagir de uma forma funcional perante as dificuldades próprias da profissão, tornando-se profissionais engaged, ou seja, enquanto alguns professores vivenciam as dimensões negativas do burnout (exaustão emocional, despersonalização e perda de realização profissional), outros experienciam as três dimensões positivas do engagement (vigor, dedicação e absorção profissional). Com a entrada da chamada "psicologia positiva”, surge uma nova perspectiva de estudo que procura respostas para determinadas formas de envolvimento profissional. Assim, apesar do fenómeno do engagement ainda não estar muito estudado, encontrar professores engaged com a sua profissão também é uma realidade presente em muitos países. 0 recurso a estratégias de coping é uma forma de lidar com as dificuldades inerentes ao exercício da profissão docente. Logo, é importante perceber de que forma a utilização de determinado tipo de estratégia de coping poderá conduzir ao burnout ou, preferencialmente, ao engagement.

\section{Palavras-chave}

Burnout - Engagement - Coping - Professores.

Correspondência:

Célia Xavier Perestrelo

Rua Levada do Cavalo, $n^{\circ} 23$,

Ed. K5. BI. 4 - Z

9000-174 Funchal - Portugal

E-mail: celia.perestrelo@gmail.com 


\title{
An essay on burnout, engagement, and coping strategies in the teaching profession
}

\author{
Margarida Pocinho \\ Célia Xavier Perestrelo \\ University of Madeira
}

Contact:

Célia Xavier Perestrelo

Rua Levada do Cavalo, $n^{\circ} 23$,

Ed. K5. BI. 4-Z

9000-174 Funchal - Portugal

E-mail: celia.perestrelo@gmail.com

\begin{abstract}
Researchers throughout the world have started to worry about the phenomenon of burnout, identifying it mainly in professions that involve a relation of assistance or help, as in the case of medical doctors, nurses, and psychologists. However, it was not long before it was noticed that such phenomenon can also be present in the teaching profession in a very significant way. Teaching is nowadays one of the professions subjected to the highest levels of stress, which can lead to burnout when the situation becomes recurrent. Many teachers manage to adapt and to react in a functional way when faced with the difficulties inherent to their profession, becoming engaged professionals, that is to say, while some teachers experience the negative dimensions of burnout (emotional exhaustion, depersonalization, and loss of professional fulfilment), others experience the three positive dimensions of engagement (vigor, dedication, and absorption in the profession). With the arrival of the so-called "positive psychology", there comes a new perspective of investigation, which seeks to give answers to certain forms of professional involvement. Thus, despite the fact that the phenomenon of engagement has still been little studied, to find teachers engaged with their profession is also a reality in many countries. Resorting to strategies of coping is one way of dealing with the difficulties inherent to the exercise of the teaching profession. Therefore, it is important to observe in which way the use of certain type of strategy of coping can lead to burnout or, preferably, to engagement.
\end{abstract}

\section{Keywords}

Burnout - Engagement - Coping - Teachers. 


\section{Introdução}

A investigação científica na área da educação, de modo geral, procura respostas para os grandes problemas junto das crianças, tentando perceber de que forma aprendem, como experienciam as vivências académicas, tentando solucionar a problemática do insucesso escolar e as dificuldades generalizadas da educação enquanto sistema organizacional. Porém, estudos que procuram compreender o outro lado da questão, nomeadamente estudos realizados junto dos professores, centrando as suas questões não unicamente na forma como estes profissionais ensinam, mas essencialmente na forma como sentem e vivenciam a sua vida profissional, começam a proliferar por todos os continentes.

O stresse na profissão é um facto. É também um facto que muitos professores abandonam a profissão antes da idade da reforma ou mesmo nos primeiros anos de vida profissional. Esta situação é de tal forma preocupante que os diretores da United Nations Educational, Scientific and Cultural Organization (Unesco), da United Nations Children's Fund (Unicef), do Programa das Nações Unidas para o Desenvolvimento (PNUD), da Organização Internacional do Trabalho (OIT) e da Internacional da Educação na mensagem divulgada quando da comemoração do Dia Mundial dos Professores, em 2010, manifestaram a sua preocupação com a escassez de professores que se começa a verificar por todo o mundo. Se este fenómeno não for devidamente estudado para que o possamos prevenir, as organizações mundiais temem que não seja possível cumprir as Metas de Desenvolvimento do Milénio (MDM) e as metas da Educação para Todos (EPT), pois, prevê-se que o mundo precisa de sensivelmente 9,1 milhões de novos professores para alcançar as metas de educação internacionalmente acordadas para $2015^{1}$.

1. Disponível em: <http://www.unesco.org/pt/brasilia/dynamic-contentsingle-view/news/joint_message_on_the_world_teachers_day_2010/ back/9683/cHash/9923a5b104/>. Acesso em: 29/06/2001.
Se existem formas de lidar com o stresse (CAPELO, 2010; POCINHO, CAPELO, 2009), e que podem melhorar a qualidade de vida dos professores, o mais preocupante é quando se atinge o burnout. 0 que está na base desta síndrome e como preveni-la e/ou remediá-la? Assim, interessou, com este trabalho, fazer uma revisão dos estudos académicos publicados sobre burnout, engagement e estratégias de coping, não só na Europa, mas um pouco por todo o mundo, de modo a melhor compreendermos a forma como estes fenómenos estão relacionados e como podem contribuir para o mal-estar ou bem-estar docente.

\section{Burnout}

0 estudo do burnout ou desgaste profissional teve início com os artigos de Freudenberger (1974), nos quais o autor relata a experiência de exaustão de energia que observava nos voluntários e profissionais em funções assistenciais e de ajuda quando estes se sentiam sobrecarregados pelos problemas dos pacientes. Mais tarde, no início dos anos 80, na Califórnia, Maslach e Jackson estudaram este fenómeno psicológico e, após os resultados das suas investigações, conceberam o burnout como uma resposta ao stresse ocupacional crónico, que compreende a experiência de se encontrar emocionalmente esgotado, o desenvolvimento de atitudes e sentimentos negativos para com as pessoas com as quais se trabalha, bem como com o próprio desempenho profissional. A relação do trabalhador com a profissão vai se degradando, o entusiasmo inicial dá lugar a uma enorme vontade de evitar o local de trabalho e de manter relações com os intervenientes e o sentimento de capacidade para o exercício profissional passa a ser subjugado.

Atualmente, a definição mais unânime do burnout ou síndrome de exaustão é a alicerçada na perspectiva social-psicológica de Maslach e colaboradores (1996), sendo esta constituída de três dimensões: exaustão emocional, despersonalização e baixa realização pessoal 
no trabalho. A exaustão emocional é descrita por sentimentos de esgotamento emocional e físico; trata-se de reconhecer que não se dispõe de força vital para prosseguir com as atividades laborais, o quotidiano profissional passa a ser penoso, doloroso, impossível. A despersonalização revela-se através de atitudes de distanciamento emocional em relação às pessoas a quem se deve prestar serviços e aos colegas de trabalho; os contactos tornam-se impessoais, desprovidos de afetividade, desumanos, e, por vezes, estes profissionais passam a apresentar comportamentos ríspidos, cínicos, irónicos. A realização profissional decresce, perdendo a satisfação, o contentamento e a eficiência no trabalho; há um sentimento de insatisfação profissional, o trabalho perde o sentido e passa a ser um fardo; há uma tendência do trabalhador se autoavaliar de forma negativa. As pessoas sentem-se infelizes consigo próprias e insatisfeitas com o seu envolvimento profissional.

O burnout poderá ser confundido com o stresse, mas distingue-se na medida em que, segundo Maslach e Schaufeli (1993), é visto como o prolongamento do stresse profissional, sendo o culminar de um processo de longa duração, em que o indivíduo sente que já não lhe restam recursos para lidar com a sua situação profissional. 0 stresse está intimamente ligado a um processo de adaptação provisório e é caracterizado por sintomas mentais e físicos; já o burnout, está relacionado com uma quebra na adaptação acompanhada de mau funcionamento crónico. Ou seja, se por um lado o stresse apresenta características funcionais na medida em que pode otimizar o funcionamento adaptativo (eustresse), quando, perante uma situação stressante, o indivíduo consegue ser bem-sucedido, tornando-se mais confiante e mais capaz de fazer face a situações semelhantes, por outro lado, também tem características adversas, quando traduz uma má adaptação recorrente das exigências da vida (distresse), quer profissionais, quer sociais (JESUS, 2002). Ora, o burnout situa-se exatamente neste último plano, no qual o indivíduo deixa de ser capaz de fazer face aos problemas profissionais, manifestando irritabilidade, falta de empenho e de interesse profissional.

Muitas vezes confundido com a depressão devido à semelhança dos sintomas, o que distingue estes dois estados emocionais, embora a depressão possa alterar-se e conduzir ao burnout, é que, ao contrário da pessoa profissionalmente esgotada, o indivíduo depressivo vê todas as esferas da sua vida atingidas por esse estado de prostração (DELBROUCK, 2006). 0 indivíduo com burnout pode até mesmo vivenciar, ao nível pessoal e social, experiências enriquecedoras e gratificantes, mas não o consegue fazer ao nível profissional. Embora o burnout possa de alguma forma influenciar a vida pessoal e social, há uma clara distinção entre a causa e a consequência. De uma forma geral, uma pessoa depressiva tende a se sentir culpada pelo que lhe acontece; já o indivíduo com burnout sente fúria por não conseguir lidar com a sua frustração profissional.

Os primeiros estudos relacionados com o burnout incidiam essencialmente sobre os profissionais de saúde, no entanto, sua ocorrência entre os profissionais de ensino já é superior à dos primeiros, o que coloca o ensino como uma das profissões de alto risco (OIT, 1993; PICADO, 2009). 0 burnout, atualmente, apesar de não estar identificado pelo DSM IV (Diagnostic and Statistical Manual of Mental Disorders), é reconhecido pelo ICD - 20 (International Statistical Classification of Diseases and Related Health Problems). Estes indicadores evidenciam a necessidade de cada vez mais se investir na investigação acerca do tema, de modo a melhor clarificar o conceito, suas causas e consequências, para que se possa intervir eficazmente. 0 burnout dos professores não será de todo um fenómeno isolado, pois afeta diretamente os alunos e indiretamente a sociedade.

\section{Burnout na profissão docente}

A profissão docente é claramente uma área de partilha, de experimentação, onde as relações inter e intrapessoais são imperantes, pelo que o bem-estar deverá ser predominante para 
que a aprendizagem flua. Contudo, nem sempre é assim, e o burnout nos professores afeta o ambiente educativo, interfere na obtenção dos objetivos pedagógicos, levando estes profissionais a um processo de alienação, desumanização, apatia, ocasionando problemas de saúde, absentismo e intenção de abandonar a profissão (RUDOW, 1999). Estas circunstâncias não só representam um encargo financeiro para a sociedade, mas também acabam por ser prejudiciais para os alunos e, naturalmente, para os próprios professores. Chang (2009) refere que o burnout nos professores afeta a profissão tanto ao nível externo como ao nível interno. Externamente, os danos provocados na profissão são mensuráveis e visíveis, com o desalento dos professores e a progressiva escassez destes profissionais por todo o mundo. Este facto é visível ao nível da descredibilização do ensino enquanto agente educativo e promotor de aprendizagens significativas e duradouras perante a sociedade em geral. Internamente, para alguns professores que permanecem na profissão, a fadiga pode levar a sentimentos de ineficácia e burnout que prejudicam o trabalho na sala de aula e na escola (CHANG, 2009). 0 absentismo dos professores é um indicador de que algo não está bem, as interrupções letivas parecem não ser suficientes para recarregar baterias e reaprender novas formas de lidar com as especificidades profissionais. Os alunos ficam prejudicados pelo burnout dos seus professores, uma vez que o melhor método de ensino é sem dúvida a motivação e o empenho que o professor coloca na sua arte.

0 relatório da OIT (1993) intitulado El trabajo en el mundo reconhece que stresse e síndrome de burnout não são fenómenos isolados, mas ambos tornaram-se um risco significativo na profissão docente, o que afeta os professores e os alunos. Dados revelados no referido relatório estimam que $25 \%$ a $33 \%$ dos professores sofrem de stresse de forma significativa. Na Grã-Bretanha, o número de professores que abandona a profissão é maior do que o número de professores que fica até a idade da reforma, e 20\% dos professores têm problemas com ansiedade, depressão e stresse.

A revisão da literatura faz-nos crer que o fenómeno do burnout está presente nos professores de todos os níveis de ensino, afetando os mais idealistas e comprometidos com a profissão. Nesta profissão, ele é visível de forma consistente em diversos países e culturas. Na Suécia, 25\% dos educadores estão sujeitos a tensão num nível que pode ser considerado de alto risco; nos EUA, cerca de 25\% dos professores em início de carreira deixam o ensino no terceiro ano de trabalho, e quase 40\% deixam a profissão dentro dos primeiros cinco anos (CHANG, 2009). Na Alemanha, um estudo levado a cabo por Bauer et al. (2006), com uma amostra de 408 professores do ensino secundário, mostra que 32,5\% dos professores sofrem de burnout. Na Espanha, Manassero et al. (2003), numa investigação com 614 professores, constataram que cerca de $40 \%$ dos docentes são afetados por altos níveis de burnout. Durán et al. (2005) verificaram, num grupo de 265 professores do ensino básico e secundário, que estes apresentavam níveis intermédios da doença.

Em Portugal, a investigação no âmbito do burnout começa a ser alvo de interesse, e, assim, as publicações são cada vez mais numerosas e em diferentes grupos. Num dos estudos realizados recentemente em Portugal por Marques Pinto, Lopes da Silva e Lima (2003), com uma amostra de 777 professores da educação básica e do ensino secundário, concluíram que 54\% dos inquiridos percepcionam a docência como uma atividade muito ou extremamente geradora de stresse. No que diz respeito à observação da incidência do burnout, os professores portugueses manifestaram níveis inferiores relativamente aos dados normativos (EUA), especialmente nas dimensões de exaustão emocional e despersonalização (MARQUES PINTO et al., 2003). A investigação de Mota-Cardoso et al. (2002), também realizada em Portugal, com uma amostra de 2.108 professores, reconheceu que $34,80 \%$ dos professores tinham 
altos níveis de exaustão, 84,20\% falta de realização pessoal e 6,30\% tinham níveis de despersonalização elevados. Os autores concluem que entre $6,30 \%$ e $34,80 \%$ dos professores podem estar a sofrer de maneira grave ou moderada da síndrome.

Estes dados são de facto preocupantes, visto tratar-se de uma profissão que lida com vidas humanas. É uma profissão que faz crescer, transmite valores e atitudes, desenvolve o indivíduo e transforma uma sociedade. Quando um único professor se encontra em estado de burnout, isso significa que, no caso específico de Portugal, tratando-se do $1^{\circ}$ ciclo (monodocência), pelo menos 25 alunos serão afetados; no caso do $2^{\circ}, 3^{\circ}$ ciclo e ensino secundário; serão cerca de 125 alunos (partindo do princípio de que cada professor, nestes niveis de ensino, tenha a seu cuidado cinco turmas com 25 alunos cada).

\section{Variáveis associadas ao burnout}

Muitas são as variáveis associadas ao burnout nos docentes. Apesar de não ser consensual, o género é uma variável que influencia a sindrome na docência. Segundo Picado (2007), fundamentado numa amostra de 400 professores portugueses do $1^{\circ}$ ciclo do ensino básico, os docentes do sexo masculino apresentam níveis de despersonalização mais elevados do que os professores do sexo feminino; no entanto, os níveis de maior satisfação profissional, maior suporte social e apoio dos colegas são mais visíveis no género feminino. Na Espanha, Fernández-Castro, Doval e Edo (1994) encontraram maiores índices de burnout em mulheres.

Quanto à idade, a pesquisa mostrou que os professores mais jovens obtiveram pontuações significativamente mais elevadas que os professores mais velhos no que concerne à exaustão emocional (MASLACH et al., 1996). No entanto, os efeitos da idade foram controversos para a despersonalização e realização pessoal. Maslach e colaboradores (1996) constataram que os profissionais mais jovens foram mais desumanos e apresentaram níveis significativamente mais baixos de realização profissional do que os seus colegas mais velhos. Também Friedman e Farber (1992) referem que os professores com idades compreendidas entre os 20 e os 30 anos têm uma maior propensão para o burnout que os professores que se encontram na faixa etária dos 30/40 anos, especialmente nas dimensões de exaustão emocional e despersonalização, e os professores com mais de 45 anos apresentaram níveis significativamente mais baixos de realização profissional.

Outras características demográficas encontradas relativamente ao burnout docente incluem o estado civil, sendo os professores solteiros mais propensos ao burnout (MASLACH, JACKSON, 1996). Marques Pinto (2003) verificou que os docentes solteiros apresentam níveis significativamente mais elevados de despersonalização do que os docentes casados ou divorciados e não revelam níveis significativamente mais elevados de exaustão emocional.

No que toca às variáveis profissionais, o estudo realizado por Friedman (1991) identificou que, quanto maior a experiência profissional do professor, menores eram os níveis do burnout. 0 sentimento de mal-estar docente surge associado ao "choque com a realidade", uma vez que os professores não são suficientemente preparados para fazer face à realidade, sendo esta demasiado idealizada na fase inicial de formação (JESUS, 2002).

Em suma, os professores mais sujeitos a burnout terão entre os 20 e os 30 anos, são solteiros e encontram-se na fase inicial da sua carreira. Contudo esta conclusão não passa de uma mera generalização, porque, efetivamente, a literatura comprova que o burnout existe também em professores mais velhos, casados e com mais experiência profissional, embora com menor incidência.

\section{Causas de burnout}

Torna-se, portanto, imperante perceber as causas associadas ao burnout, pois desta forma será possível desenhar programas de inter- 
venção que vão ao encontro das necessidades profissionais na docência. Consequentemente, investigações realizadas na Austrália, Nova Zelândia, Canadá, Holanda, Reino Unido, Israel, nos Estados Unidos, entre outros países, têm procurado encontrar causas semelhantes de burnout nos docentes. Desta feita, verificamos que a carga excessiva de trabalho, as más condições laborais, com as salas de aula superlotadas, locais de trabalho pobres e falta de recursos físicos e humanos são fatores preditores de stresse e burnout (CARSON, 2006 apud CHANG, 2009; JESUS, 2002; PICADO, 2007). Manter a disciplina, a falta de apoio administrativo, isto é, o mal-estar provocado pela falta de ambiente amigável entre os funcionários e pela falta de apoio social dos colegas e da administração, a rigidez organizacional, a falta de participação dos professores nas decisões da vida escolar e, em última instância, a falta de oportunidade de subir na carreira também são vistas, pelos professores, como uma razão para o burnout. Por outro lado, constantemente, novas leis e estatutos são criados, o que implica novos procedimentos na prática de tarefas e funções, conduzindo colegas de trabalho a relações tensas e conflituosas, por falta de apoio tanto das supervisões quanto das próprias organizações (GIL-MONTE, 2002; JESUS, 2002; MASLACH, SCHAUFELI, LEITER, 2001). Todos estes aspectos propiciam um clima de tensão ideal ao desenvolvimento da síndrome e parecem ser comuns em todos os países onde o fenómeno de burnout tem sido estudado, desde os países mais desenvolvidos, aos países com menos condições socioeconómicas. Por outro lado, a opinião pública também é um fator de indução de burnout, já que, embora nem todos nós sejamos professores, todos nós passamos pela vivência escolar e sabemos, de uma forma ou de outra, o que é ser professor, o que faz e como faz, logo é muito mais fácil opinar e criticar a atuação de um professor do que, por exemplo, a de um engenheiro ou outro profissional mais específico, acerca do qual não temos qualquer tipo de conhecimento vivenciado. Quando algo corre mal na escola, é notícia de abertura do telejornal, no entanto, muitos são os sucessos que ficam apenas entre as paredes da escola.

\section{Engagement}

Se, por um lado, é verdade que uma grande percentagem de professores sofre de stresse crónico e burnout, por outro lado, continuamos a encontrar muitos professores satisfeitos com a sua profissão, entusiasmados, motivados e empenhados em melhorar cada vez mais as suas práticas em prol de um ensino de qualidade. É partindo destes pressupostos que, por todo o mundo, investigadores têm olhado para este lado da questão, ou seja, começam a ter em conta as qualidades positivas da vida, em detrimento das patologias e dos défices. Surge assim uma nova era, a da chamada "Psicologia Positiva”, na qual se enquadra o engagement. Este constructo, enquanto fenómeno positivo, tem sido caracterizado por um estado de vigor, dedicação e absorção (SCHAUFELI, BAKKER, 2004). $O$ vigor equivale à manifestação de altos níveis de energia, de um grande desejo de esforço e de uma perseverança na concretização das tarefas. A dedicação envolve fortes níveis de entusiasmo, inspiração, orgulho e desafio no trabalho. 0 estado de absorção refere-se a elevados níveis de concentração e de felicidade durante o desempenho da atividade laboral (BAKKER et al., 2007; SCHAUFELI, BAKKER, 2004; SCHAUFELI, SALANOVA, 2007).

0 engagement no trabalho é distinto de outros constructos da psicologia das organizações, como o compromisso organizacional, a satisfação no trabalho ou o envolvimento no trabalho (MASLACH et al., 2001). 0 compromisso organizacional refere-se a uma lealdade do trabalhador em relação à organização que fornece o emprego. 0 foco coloca-se na organização e incide sobre o próprio trabalho. A satisfação no trabalho ocorre quando a situação profissional é vista como uma fonte de realiza- 
ção e contentamento, ou um meio de libertação em face de situações causadoras de aborrecimento e insatisfação, mas não abrange a relação da pessoa com o próprio trabalho. 0 envolvimento no trabalho é semelhante à dimensão da dedicação no engagement, mas não inclui as dimensões de vigor e absorção (MASLACH et al., 2001). Por último, o engagement, na dimensão de absorção, aproxima-se daquilo a que se pode chamar de "flow", um termo usado por Csikszentmihalyi (1990) que representa um estado ótimo de experiência caracterizado por uma atenção especial, uma mente clara e uma harmonia com o corpo, concentração sem esforço, perda de autoconsciência, distorção do tempo e prazer intrínseco.

A literatura fala-nos em duas correntes distintas de pensamento relativamente ao engagement. Maslach e Leiter (1997), citado por Bakker et al. (2007), partem do princípio de que o burnout e o engagement são extremidades opostas de um contínuo - de um lado, a exaustão e, do outro, o vigor, que diz respeito à dimensão de ativação ou energia; e o contínuo que tem início na despersonalização e o fim na dedicação, ou seja, a dimensão da identificação. 0 engagement é representado pelo vigor (elevada ativação) e pela dedicação (elevada identificação) (BAKKER et al., 2007; SCHAUFELI et al., 2002). Desta forma, o vigor e a dedicação são duas dimensões do engagement e são vistas como polos opostos da exaustão e da despersonalização, duas das dimensões principais do burnout. Na perspectiva de Maslach e Leiter (1997), referido por Bakker et al. (2007), o engagement é avaliado pelo comportamento inverso dos valores obtidos através das três dimensões avaliadas pelo Maslach Burnout Inventory (MBI), ou seja, baixa pontuação em exaustão e despersonalização, e valores elevados de realização profissional são indicadores de engagement e elevada pontuação em exaustão e despersonalização e baixos valores de realização profissional significam que existe burnout.
A outra corrente de pensamento vê o engagement como uma oposição ao burnout, mas considera estes fenómenos independentes (SCHAUFELI, BAKKER, 2004). Ou seja, o engagement no trabalho é caracterizado por uma harmonia entre a parte afetiva e a parte cognitiva do indivíduo, mas não se foca num objeto em particular, num evento, num indivíduo ou comportamento. Espelha um estado da mente da pessoa no momento presente. É distinto de um traço da personalidade, tem uma disposição durável e reflete uma reação típica da pessoa (SCHAUFELI, SALANOVA, 2007). Segundo esta perspectiva, o burnout e o engagement são avaliados de forma independente, através da utilização de diferentes instrumentos, e o estudo do engagement é operacionalizado através da utilização da Utrecht Work Engagement Scale (UWES), um questionário que inclui as três dimensões: vigor, dedicação e absorção.

Todavia, esperar que ambos os constructos estejam correlacionados negativamente de forma perfeita não é realista. Ou seja, avaliar o engagement e o burnout numa única escala, como defendem Maslach e colaboradores, é demasiado redutor. Quando um indivíduo não está afetado pelo burnout não significa que esteja numa situação de engagement profissional. Por outro lado, baixas pontuações em engagement não traduzem um estado de burnout. Por conseguinte, a relação estabelecida entre os dois constructos não pode ser empiricamente estudada quando são medidos com o mesmo questionário. Os dois conceitos devem ser avaliados em modelos diferentes para que se possa efetivamente perceber em que níveis se situam os profissionais em estudo, de modo a melhor se definir uma intervenção, se tal for necessário. Efetivamente é possível encontrarmos docentes que não estão engaged, mas também não estão em estado de burnout; contudo, à partida, o ideal será apostar na promoção do engagement em todos os docentes, já que o bem-estar profissional é um aliado das boas práticas. 


\section{Características dos trabalhadores engaged}

Os profissionais que apresentam engagement são descritos por um sentido de energia e eficácia relacionado com as suas atividades profissionais e sentem-se capazes de lidar com as exigências do trabalho. Apresentam uma boa saúde mental e psicossomática, são proativos, mostram iniciativa no trabalho, são motivados, estão atentos às mudanças no seu trabalho e adaptam-se facilmente a novas situações (SALANOVA, SCHAUFELI, 2008). Valorizam os aspectos intrínsecos do trabalho e os recursos do mesmo, os aspectos interpessoais e as recompensas, utilizam estratégias de coping eficazes e trabalham afincadamente, pois gostam muito daquilo que "fazem", são caracterizados por altos níveis de neuroticismo, encadeados com altos níveis de extroversão. Diferenciam-se dos workaholics por não serem obcecados pelo trabalho (SCHAUFELI et al., 2001 citado por BAKKER et al., 2007); embora despendam muitas horas a trabalhar, não negligenciam a sua vida social fora do trabalho.

0 engagement no trabalho acarreta benefícios tanto ao nível individual como ao nível organizacional (SCHAUFELI, SALANOVA, 2007). Ao nível individual, tem um papel fundamental na promoção da saúde dos trabalhadores, conduz a atitudes e emoções positivas face ao trabalho, aumenta a motivação intrínseca, suscita uma maior identificação do sujeito com a sua atividade, origina comportamentos proativos positivos e um desempenho de excelência, fomenta a aprendizagem de novos recursos laborais e pessoais, nomeadamente a autoeficácia. Todos estes aspectos acabam por ser transportados para a vida pessoal dos trabalhadores, o que sem dúvida contribui para a saúde e bem-estar geral dos profissionais e daqueles que os rodeiam, tanto na vida pessoal como laboral. Ao nível organizacional, possibilita incrementar comportamentos organizacionais positivos, orienta na prossecução de políticas de gestão de recursos humanos (SCHAUFELI, SALANOVA,
2007), contribui para o sucesso da organização, uma vez que está relacionado com resultados positivos no trabalho, tais como o compromisso organizacional, a qualidade de desempenho elevada, a produtividade, o baixo absentismo, a satisfação e lealdade do cliente, a falta de desejo de mudar de profissão e a segurança (BAKKER et al., 2007). Evidentemente que, tratando-se da profissão docente, os benefícios se estendem a toda a sociedade, já que professores engaged contagiam os seus alunos, que facilmente se envolvem nas suas aprendizagens e, por sua vez, irão espelhar o seu engagement enquanto cidadãos participativos, empenhados na construção de uma sociedade mais democrática.

\section{Estudos realizados sobre 0 engagement com professores}

Apesar do engagement no trabalho ser um conceito recente e de ainda não haver muitos estudos acerca do tema, podemos, contudo, com base na bibliografia existente, encontrar algumas investigações que comprovam a existência de engagement no trabalho em diversas áreas, incluindo a docência. Durán et al. (2005), numa investigação realizada na Espanha no âmbito do engagement com professores do ensino básico, secundário e de adultos, verificaram que os valores de engagement são consideravelmente altos, com pontuações de média de resposta de 5,03 para a dimensão de vigor, de 4,94 para a dedicação e de 4,71 para a eficácia, num intervalo de respostas determinado entre 0 e 6 . Nesta investigação, os autores observaram analogias entre as categorias do engagement e do burnout e a satisfação laboral e vital, sendo de realçar a vantagem das três categorias do engagement, e em especial da dedicação, que surge como ponto fulcral no que concerne à harmonização positiva do bem-estar psicológico dos trabalhadores. Estes resultados vão ao encontro dos estudos de Schaufeli e colaboradores (2002), nos quais se verificou que os profissionais que manifestavam maior vigor, dedicação e absorção 
reagiam mais positivamente diante do stresse. Em Portugal, Picado (2007) verificou que a dimensão de dedicação é, das três, a que manifesta valores mais elevados, uma vez que a média de resposta é de 5,83 e a análise de distribuição das frequências mostra que $97,2 \%$ das respostas se situam acima do valor central da escala de cinco pontos utilizada. A dimensão de vigor apresenta uma média de 4,87 e 84.9\% das respostas acima do ponto 3 da escala. Finalmente, a dimensão de absorção surge com uma média de 3,74 e $58.9 \%$ das respostas abaixo do ponto 4. Estes resultados são animadores e comprovam que, embora existam muitos professores com burnout, por outro lado, também existem muitos professores engaged, pelo que é possível, através da formação inicial e contínua, promover o engagement nesta profissão, tornando-a mais atrativa para todos os intervenientes.

\section{Coping}

Se, por um lado, temos o burnout como fenómeno perturbador do bom desenvolvimento profissional causado pelo stresse crónico e, por outro, o engagement que proporciona sentimentos de bem-estar resultantes de uma adaptação eficaz ao stresse, importa compreender que variáveis medeiam estes dois fenómenos. Assim, sendo o coping a tradução dos esforços despendidos pelos indivíduos para lidar com situações causadoras de stresse crónico ou agudo, será pertinente conhecer que aspectos deste constructo influenciam as relações laborais. É no âmbito da psicopatologia que surgem os primeiros estudos relativos ao coping, e derivavam da avaliação dos processos inconscientes dos indivíduos. Esta concepção surge no século XIX, relacionada com a ideia de "defesa" largamente divulgada pela psicanálise. Contudo, segundo Capelo e Pocinho (2009), o conceito de coping deixa de ser pensado na qualidade de "defesa" a partir dos anos 60 do século XX, e passa a ser considerado como estratégias conscientes que o indivíduo adota para dar resposta às diferentes formas de stresse.
Durante os anos 70 e 80 do século XX, o estudo do coping começou a alargar os seus horizontes com a implementação de uma nova perspectiva, defendida por Lazarus (1986), que coloca a tónica na avaliação cognitiva que a pessoa faz sobre os diferentes elementos do problema, distanciando o coping dos mecanismos de defesa e da patologia (FOLKMAN, MOSKOWITZ, 2004). As investigações realizadas passam a considerar os fatores contextuais, deixando de estar centradas exclusivamente no mundo interno do indivíduo. Posto isto, o coping permite encontrar diferentes formas de lidar com as situações que ocorrem entre o indivíduo e o meio, passando a ser visto segundo uma perspectiva socioecológica. Deixa então de ser pensado como uma resposta intuitiva a um estímulo, passando a ser visto como uma resposta racional, ou seja, as estratégias de coping podem ser aprendidas e ajustadas às diferentes situações.

Folkman et al. (1986) definem o coping como a diligência que cada um faz para lidar com as pressões diárias, ou seja, os esforços cognitivos e comportamentais desenvolvidos pelo indivíduo para regular (reduzir, minimizar, dominar ou tolerar) as exigências internas e externas das transações pessoais que são percepcionados como transcendentes aos recursos individuais. Podemos entender, desta forma, que o coping é um fenómeno adaptativo que possibilita a adequação e acomodação do indivíduo ao desempenho das suas atividades em diversas vertentes da vida.

Em 1986, Latack, devido à inexistência de instrumentos de avaliação das estratégias de coping em contexto profissional, elaborou uma escala que avaliava a frequência com que cada indivíduo utilizava determinadas estratégias. Desta forma, o autor conceptualiza as categorias de coping do seguinte modo: controlo ou confronto, que consiste em ações e reavaliações cognitivas proativas assentes na situação de stresse; escape ou evitamento, que se baseia em ações e cognições que sugerem evitamento e/ou reavaliação da situação; e 
ainda gestão de sintomas, alicerçadas em estratégias para gerir os sintomas ligados ao stresse profissional em geral, verificada nos indícios de stresse ou estados psicofisiológicos.

Por conseguinte, as estratégias de coping centradas na resolução de problemas (controlo ou confronto) contribuem para uma maior manutenção da saúde física e psicológica dos indivíduos, pois permitem que ele haja sobre a situação, dando-lhe a possibilidade de controlar os níveis de stresse. Quanto às estratégias de evitamento, embora possam conter um caráter adaptativo a curto prazo, em situações adversas, a médio e longo prazo, podem corresponder a efeitos negativos (SCHAUFELI, ENZMANN, 1998). Já as estratégias de gestão de sintomas representam as ações do indivíduo, após avaliação cognitiva, para lidar com as situações (MASLACH et al, 1996); podem conter um caráter adaptativo, caso correspondam a ações que veiculem a saúde do indivíduo, ou, pelo contrário, poderão ser indicadoras de patologia. A adoção de diferentes estratégias de coping traduz-se em diferentes resultados, de acordo com o paradigma em que essas estratégias se enquadram e com a forma como o sujeito vivencia a situação, ou seja, conforme a considera controlável, incontrolável, ou recorrente. Não podemos, portanto, falar em boas ou más estratégias de coping, temos de avaliá-las tendo em conta os resultados na saúde e bem-estar do indivíduo.

\section{Estratégias de coping utilizadas pelos professores}

Existem alguns estudos empíricos que procuram identificar estratégias utilizadas pelos docentes para fazer face ao stresse. Alguns pretendem ainda explorar a eficácia de tais estratégias relativamente ao estado de saúde-doença dos professores (CAPELO, POCINHO, 2009; MARQUES PINTO; LIMA; LOPES DA SILVA, 2005; POCINHO, CAPELO, 2009).

É consensual que a procura de conselhos, vista como estratégia de gestão do stresse, e a ação direta em face dos stressores relacionam-se com níveis de mal-estar mais baixos; por outro lado, ignorar alguns aspectos da situação motiva uma forma eficaz de aligeirar a relação entre o stresse profissional dos professores e os seus indicativos psicossomáticos (BURKE et al., 1996; GREENGLASS et al., 1995; GREENGLASS et al., 1996; NEEDLE, GRIFFEN; SVENDSEN, 1981; SCHONFELD, 1990, referidos por Marques Pinto et al., 2003). Jesus e Pereira (1994), pioneiros em Portugal da investigação sobre as estratégias de coping usadas pelos docentes para resistirem ao mal-estar ocupacional, converteram uma versão traduzida do Coping Job Scale de Latack (1986), tornando este instrumento de avaliação acessível a todos os investigadores portugueses. Na sequência desta investigação, eles apuraram que os inquiridos adotavam mais frequentemente estratégias de controlo proativas, consideradas positivas pela sua componente adaptativa, em contexto profissional, seguindo-se as de escape ou de evitamento e, por fim, as de gestão de sintomas. Estes resultados foram verificados em outras investigações, realizadas por Capelo (2010), Pocinho e Capelo (2009) e Quirino (2007) tanto em Portugal Continental como na Ilha da Madeira, onde as principais formas de coping utilizadas pelos professores foram, igualmente, estratégias de controlo ou confronto, seguidas de estratégias de escape ou evitamento e, por último, as estratégias de gestão de sintomas. Os resultados destes estudos apontam também para níveis mais baixos de stresse nos professores que adotam mais estratégias de coping de controlo ou confronto.

0 trabalho realizado por Marques Pinto et al. (2005) refere que, relativamente às estratégias de coping mais utilizadas pelos professores, em primeiro lugar apresenta-se o coping centrado na resolução de problemas, incluindo estratégias de planificação, reinterpretação positiva e coping ativo, globalmente adaptativo e funcional, seguido de estratégias de regulação emocional, como a procura de suporte social e a focagem e expansão de emoções, que podem se tornar disfuncio- 
nais quando a situação requer a utilização de estratégias mais ativas. Por último, de forma menos reiterada, o recurso a estratégias de negação e evitamento, como, por exemplo, desinvestimento mental e comportamental, as quais tendem a manifestar alguma disfuncionalidade.

Quando confrontamos investigações onde foi estudada a relação entre as estratégias de coping utilizadas pelos docentes em situação de stresse profissional e de burnout, encontramos resultados semelhantes aos referidos anteriormente. Yela (1996) verificou que os professores com maiores níveis de exaustão emocional utilizavam mais sistematicamente estratégias de coping de desinvestimento mental e comportamental (ou seja, estratégias de evitamento), de inibição do coping de controlo e expansão das emoções, demonstrando, assim, a ideia de que os docentes com burnout usam estratégias de coping passivo. Por outro lado, Mazon, Carlotto e Câmara (2008), num estudo com uma amostra de 93 professores, verificam que, quanto maior a utilização de estratégias de coping de escape ou evitamento baseadas na procura de suporte emocional, foco na emoção e desligamento mental, maior é o sentimento de exaustão emocional. Já os professores que adotavam mais estratégias de coping de controlo ou confronto apresentavam menor sentimento de despersonalização. A investigação mostra que utilizar coping ativo, procurar suporte emocional e fazer reinterpretação positiva das situações stressoras aumentam o sentimento de realização profissional.

Diante do exposto, parece ser consensual, em toda a literatura, que as estratégias focadas na resolução do problema, que procuram reavaliar a situação stressora, exercitando formas de adaptação e acomodação do indivíduo ao stresse, são mais funcionais. Desta forma, será importante perceber de que modo a personalidade individual interfere na adoção e escolha das estratégias e perceber até que ponto o treino, através de programas de formação estruturados, poderão favorecer a adoção de estratégias de coping focadas na resolução dos problemas. Esta será sem dúvida uma perspectiva a adotar no âmbito da psicologia positiva, que centra a questão nos resultados e não nos problemas.

\section{Conclusão}

Em suma, podemos afirmar que, quanto mais estratégias de coping de controlo ou de confronto utilizarem os professores, maior realização profissional irão sentir, podendo esta ser uma das vias de promoção do engagement profissional. Por outro lado, quanto mais estratégias de escape ou evitamento utilizarem os docentes, maiores índices de burnout irão apresentar. Efetivamente, o que se pretende é impulsionar o engagement nos professores, dado que esta é uma das vias de promoção do sucesso académico dos alunos e, consequentemente, de uma sociedade mais equilibrada, mais justa e acessivel para todos. Os trabalhos de investigação acerca destes temas começam a ser cada vez mais variados e realçam diversas medidas, umas de caráter mais institucional, como as condições físicas e monetárias da carreira docente, outras que podem ser otimizadas em programas de formação contínua de promoção do engagement profissional e, consequentemente, da saúde e bem-estar profissional.

Contudo, na nossa opinião, seria importante aprofundar até que ponto algumas estratégias de gestão de sintomas que representam as ações do indivíduo, após avaliação cognitiva, para lidar com as situações, nomeadamente "praticar exercício físico", "praticar meditação", "usar o treino de biofeedback", "fazer relaxamento", entre outras, poderão ser preditoras do bem-estar profissional, uma vez que, ao nível pessoal, as suas vantagens já são mais que comummente aceites. 


\section{Referências}

BAUER, Joaquim et al. Correlation between burnout syndrome and psychological and psychosomatic symptoms among teachers. International Archives of Occupational and Environmental Health, v. 79, p. 199-204, 2006.

BAKKER, Arnold B. et al. Job resources boost work engagement, particularly when job demands are high. Job Educational Psychology, v. 99, n. 2, p. 275-283, 2007.

CAPELO, Maria Regina; POCINHO, Margarida. Stresse, estratégias de coping e auto-eficácia em professores. Actas do I Congresso Luso-Brasileiro de Psicologia da Saúde: experiências e intervenções. Faro, 4 a 8 de janeiro de 2009. Disponível em: <http://www.eventos.ualg.pt/CIPS/programa.html>. Acesso em: 05/03/2010.

CAPELO, Maria Regina. Estrés, coping y autoeficacia en profesores de Madeira. Cadiz, 2010. Tese de doutoramento em Ciencias del Trabajo, Universidad de Cadiz.

CHANG, Mei-Lin. An appraisal perspective of teacher burnout. examining the emotional work of teachers. Educational Psychology Review, v. 21, p. 193-218, 2009. Disponível em: <http://www.springerlink.com/content/p5320216743m2356/>. Acesso em: 10/04/2010.

CSIKSZENTMIHALYI, Mihaly. Flow. The psychology of optimal experience. New York: Harper, 1990.

DELBROUCK, Michel. Síndrome de exaustão (burnout). Lisboa: Climepsi, 2006.

DURÁN, María Auxiliadora et al. Engagement y burnout en el ámbito docente: análisis de sus relaciones con la satisfacción laboral y vital en una muestra de profesores. Revista de Psicología del Trabajo y de las organizaciones, v. 21,p. 145-158, 2005.

FERNÁNDEZ-CASTRO, Jordi; DOVAL, Eduardo; EDO, Silvia. Efectos del estrés docente sobre los hábitos de salud. Ansiedad y Estrés, Valencia, 127-133, 1994.

FOLKMAN, Susan et al. Appraisal, coping, health status, and psychological symptoms. Journal of Personality and Social Psychology, v. 50, p. 571-579, 1986.

; MOSKOWITZ, Judith Tedlie. Coping: pitfall and promises. Annual Review of Psychology, v. 55, p. 745-774, 2004.

FREUDENBERGER, Herbert J. Staff burn-out. Journal of Social Issues, 30, p. 159-165, 1974.

FRIEDMAN, Isaac A. High and low burnout schools: school culture aspects of teacher burnout. Journal of Educational Research, v. 84 , n. 6 , p. 325-333, 1991.

; FARBER, Barry A. Professional self-concept as a predictor of teacher burnout. Journal of Educational Research, v. 86, n. 1, p. 28-29, 1992.

GIL-MONTE, Pedro R. Influencia del género sobre el proceso de desarrollo del síndrome de quemarse por el trabajo (burnout) en profesionales de enfermería. Psicologia em Estudo, v. 7, n. 1, p. 3-10, 2002.

JESUS, Saul Neves; PEREIRA, Anabela M. Estudo das estratégias de "coping" utilizadas pelos professores. In: SEMINÁRIO A COMPONENTE DE PSICOLOGIA NA FORMAÇÃO DE PROFESSORES E OUTROS AGENTES EDUCATIVOS. 5., 1994. Actas. Évora, Portugal: Universidade de Évora, 1994, p. 253-268.

JESUS, Saul Neves. Perspectivas para o bem-estar docente: uma lição de síntese. Porto: ASA, 2002.

LATACK, Janina C. Coping with job stresse: measures and future directions for scale development. Journal of Applied Psychology, v. 71 , p. 377-385, 1986 
LAZARUS, Richard S; FOLKMAN, Susan. Stresse, appraisal and coping. New York: Springer, 1984.

MANASSERO, María A. et al. Estrés y burnout en la enseñanza. Palma de Mallorca: UIB, 2003.

MARQUES PINTO, Alexandra; LIMA, Maria Luisa; LOPES DA SILVA, Adelina. Stresse profissional em professores portugueses: incidência, preditores e reacção de burnout. Psychologica, v. 33, p. 181-194, 2003.

Como lidam os professores com o stresse profissional?: coping e burnout profissional em professores portugueses, 2005. Disponível em: <http://www.proformar.org/revista/edicao_7/pag_1.htm>. Acesso em: 09/03/2010.

MASLACH, Christina. Burnout: a multidimensional perspective. In: SCHAUFELI, Wilmar B.; MASLACH, Christina; MAREK, Tadeusz (Eds.). Professional burnout: recent developments in theory and research. New York: Taylor \& Francis, 1993, p. 19-32. Press, 1996

; JACKSON, Susan E.; LEITER, Michael P. Maslach burnout Inventory. 3rd ed. Palo Alto, CA: Consulting Psychologists ; SCHAUFELI, Wilmar B.; LEITER, Michael P. Job burnout. Annual Review Psychology, v. 52, p. 397-422, 2001.

MAZON, Vania; CARLOTTO, Mary Sandra; CÂMARA, Sheila Gonçalves. Síndrome de Burnout e estratégias de coping em professores de escolas municipais da área urbana de uma cidade do litoral norte do Rio Grande do Sul. Arquivos Brasileiros de Psicologia, v. 60, n. 1 , p. $55-66,2008$.

MOTA-CARDOSO, Rui et al. 0 stresse nos professores portugueses - Estudo IPSSO 2000. Porto: Porto, 2002.

ORGANIZAÇÃO INTERNACIONAL DO TRABALHO (OIT). El trabajo en el mundo. Trabajadores de la ensenanza, n. 157, 1993.

PICADO, Luís. Ansiedade, burnout e engagement nos professores do $1^{\circ}$ ciclo do ensino básico: 0 papel dos esquemas precoces mal adaptativos no mal-estar e no bem-estar dos professores. Lisboa, 2007. Tese de doutoramento em Psicologia. Universidade de Lisboa Faculdade de Psicologia e de Ciências da Educação. 30/03/2010.

Ser professor: do mal-estar para o bem-estar docente, 2009. Disponível em: <www.psicologia.com.pt>. Acesso em:

POCINHO, Margarida; CAPELO, Maria Regina. Vulnerabilidade ao stresse, estratégias de coping e auto-eficiência em professores portugueses. Educação e Pesquisa, v. 35, n. 2, p. 351-367, 2009.

QUIRINO, Ana. Stress, coping e burnout em professores do $3 .^{\circ}$ Ciclo. Dissertação de Mestrado em Psicologia da Saúde apresentada à Universidade do Algarve. Faro: Universidade do Algarve, 2007.

RUDOW, Bernd. Stress and burnout in the teaching profession: European studies, issues, and research perspectives. In: VANDERBERGUE, Roland; HUBERMAN, Michael A. (Ed.). Understanding and preventing teacher burnout: a source book of international practice and research. Cambridge: Cambridge University Press, 1999.

; SCHAUFELI, Wilmar B. A cross-national study of work engagement as a mediator between job resources and proactive behavior. The International Journal of Human Resource Management, v. 19, p. 116-131, 2008.

SCHAUFELI, Wilmar; ENZMANN, Dirk. The burnout companion to study and practice - A critical analysis. London: Taylor \& Francis, 1998.

SCHAUFELI, Wilmar B. et al. The measurement of engagement and burnout: A two sample confirmatory factor analytic approach. Journal of Happiness Studies, v. 3, p. 71-92, 2002.

SCHAUFELI, Wilmar B.; BAKKER, Arnold. B. Job demands, job resources, and their relationship with burnout and engagement: a multi-sample study. Journal of Organizational Behavior, v. 25, p. 293-315, 2004. 
SCHAUFELI, Wilmar B.; SALANOVA, María L. Work engagement: an emerging psychological concept and its implications for organizations. Managing Social and Ethical Issues in Organizations, p. 135-177, 2007.

YELA, José Ramón. Desgaste emocional, estrategias de afrontamiento y transtornos psicofisiologicos en profesionales de la ensenanza. Boletín de Psicologia, v. 50, p. 37-52, 1996.

Recebido em: 16.06 .2010

Aprovado em: 15.02.2011

Margarida Pocinho é doutorada em Educação, professora auxiliar do departamento de Psicologia e Estudos Humanísticos da Universidade da Madeira, Portugal. E-mail: mpocinho@uma.pt.

Célia Xavier Perestrelo é mestranda em Psicologia da Educação na Universidade da Madeira, é professora destacada na Direcção Regional de Educação da Madeira, Portugal. 